\title{
Epigrafi Indonesia: Peran, Kedudukan, Dan Pengembangannya
}

\section{Tjahjono Prasodjo}

Keywords: methods, theory, practices, inscription, archaeology, history

\section{How to Cite:}

Prasodjo, T. (1998). Epigrafi Indonesia: Peran, Kedudukan, Dan Pengembangannya. Berkala Arkeologi, 18(1), 7-16. https:/ / doi.org/10.30883/jba.v18i1.772

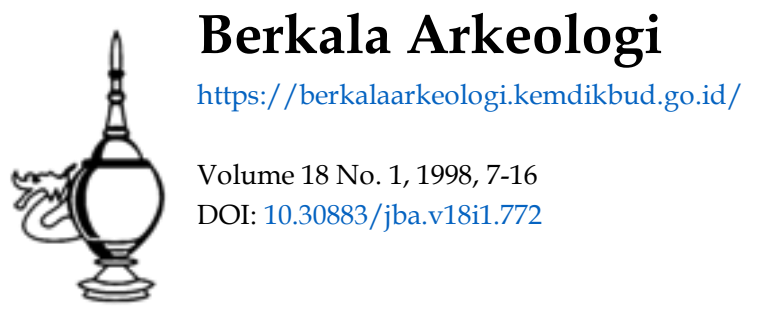

\section{(c) (i) (3)}

This work is licensed under a Creative Commons Attribution-NonCommercial-ShareAlike 4.0 International License. 


\title{
EPIGRAFI INDONESIA: \\ PERAN, KEDUDUKAN, DAN PENGEMBANGANNYA
}

\author{
Tjahjono Prasodjo \\ (Jurusan Arkeologi, Fakultas Sastra, Universitas Gadjah Mada)
}

Dalam Diskusi Ilmiah Epigrafi di Yogyakarta pada tahun 1991 Ayatrohaedi mempresen-tasikan sebuah makalah yang berjudul "Epigrafi Indonesia dan Pengembangannya". Pada bagian pertama dari makalahnya Ayatrohaedi menyoroti kedudukan epigrafi di antara arkeologi dan ilmu sejarah. Di bawah ini adalah kutipan sebagian dari pendapatnya yang memperlihatkan posisi epigrafi di antara arkeologi dan ilmu sejarah:

Sejak penelitian yang paling awal, jelas dapat disimak bahwa penelitian epigrafi senantiasa dikaitkan dengan ilmu sejarah. Bahkan, Bukchari secara sadar mengembangkan matakuliah yang diberinya judul Prasasti sebagai Sumber Sejarah. Hal itu sebenarnya, baik sadar maupun tidak, merupakan pengakuan bahwa pada dasarnya epigrafi adalah bagian dari ilmu sejarah, dan bukan bagian arkeologi.

Lebih jauh lagi, ia mengemukakan bahwa keadaan saat ini dimana epigrafi masih berada di bawah bidang arkeologi merupakan hal yang kurang wajar. Seharusnya epigrafi dikembalikan kepada induknya, yaitu ilmu sejarah (Ayatrohaedi 1991: 1-3).

Berpijak dari gagasan tersebut di atas, makalah ini ditulis untuk melihat sejauh mana sebenarnya kedudukan dan peran epigrafi dalam kajian arkeologi dan ilmu sejarah. Di samping itu, juga akan digagas seberapa luas prospek penelitian epigrafi yang masih dimilikinya.

\section{Epigrafi Indonesia: Epistemologi dan Metodologinya}

Epigrafi adalah ilmu yang mempelajari prasasti. Definisi prasasti sendiri masih menjadi silang pendapat karena sampai saat ini masih terdapat beberapa definisi yang dilontarkan oleh para ahli epigrafi dengan muatan arti yang berbeda-beda. Di dalam makalah ini saya akan mendefinisikan prasasti secara lebih luas dan yang menurut saya paling tepat, yaitu bahwa prasasti adalah tulisan kuno yang dituliskan pada media tulisan yang berbahan keras, seperti antara lain: lempengan logam, kayu, dan batu. Prasasti dapat dibedakan berdasarkan panjang pendeknya tulisan, yaitu prasasti 
panjang dan prasasti pendek. Prasasti panjang digunakan untuk menyebut antara lain prasasti yang berisi penetapan sima, sedangkan contoh prasasti pendek adalah prasasti yang memuat hanya empat atau tiga digit angka tahun. Di samping itu, prasasti juga dapat digolongkan berdasarkan atas isinya, seperti misalnya prasasti penetapan sima, prasasti peradilan (jayapattra jayasong), dan prasasti angka tahun. Ruang lingkup bahasan epigrafi meliputi antara lain: media prasasti, bahan prasasti, bentuk prasasti, isi prasasti. paleografi, struktur prasasti, pembacaan prasasti, dan penafsiran isi prasasti.

Definisi dan pengertian epigrafi di atas mengimplikasikan bahwa untuk dapat menjadi ahli epigrafi. seseorang harus membekali diri dengan tiga kemampuan pokok, yaitu: (1) mampu mengidentifikasikan prasasti, (2) mampu membaca aksara prasasti dan menterjemahkannya, dan (3) mampu memberikan tafsir terhadap isi prasasti.

Pembahasan tentang perkembangan penelitian epigrafi, termasuk metodologi penelitiannya, telah banyak dilakukan, antara lain oleh A.S. Wibowo (1976), Boechari (1977), Machi Suhadi (1982), Ayatrohaedi (1991), Richardiana Kartakusuma (1992/1993), Titi Surti Nastiti (1995), Djoko Dwiyanto (1993), dan Daud Aris Tanudirjo (1994). Oleh karena kesemua karya-karya tulis di atas berisikan bahasan terhadap metode penelitian epigrafi yang telah dipergunakan dan ditawarkan oleh peneliti-peneliti epigrafi di Indonesia selama ini, maka saya mempergunakannya untuk menyusun gambaran mengenai metode penelitian epigrafi yang dipergunakan di Indonesia sampai saat ini.

A.S. Wibowo (1976) membuat sebuah ringkasan terhadap seluruh penelitian epigrafi yang telah dilakukan sampai tahun 1960-an. Riwayat penelitian epigrafi Indonesia dalam kurun waktu tersebut dibaginya dalam dua periode besar, yaitu periode sebelum berdirinya Dinas Purbakala, dan periode sesudah berdirinya Dinas Purbakala. Penelitipeneliti yang termasuk dalam periode pertama antara lain T.S. Raffles, C.J. Van der Vlis, Rh. Th. Friederich, H. Kern, K.F. Holle, dan A.B. Cohen Stuart. Peneliti-peneliti tersebut meneliti prasasti-prasasti Indonesia dengan cara melakukan pembacaan dan penterjemahan, kecuali Friederich dan Kern yang melakukan penelitian lebih jauh dengan membuat tafsiran atas isi prasasti-prasasti yang dibaca dan diterjemahkan. Periode kedua merupakan tahap perkembangan penelitian epigrafi yaing sangat intensif. Tokoh-tokoh penelitinya antara lain J.L.A. Brandes, N.J. Krom, F.D.K. Bosch, W.F. Stutterheim, Poerbatjaraka, P.V. van Stein Callenfels, R. Goris, J.G. de Casparis, L.Ch. Damais, dan beberapa peneliti di luar Dinas Purbakala seperti B.Ch. Chabra, J.Ph. Vogel, H.Bh. Sarkar, G. Coedes, serta F.H. Van Naerssen. Tahap yang kedua ini ditandai dengan maraknya para peneliti untuk lebih banyak mengkonsentrasikan usahanya dalam merekonstruksi sejarah Indonesia Kuno, dan 
melakukan pendekatan-pendekatan sosial dan ekonomi untuk menganalisis isi prasasti. Percepatan penelitian epigrafi pada tahap kedua ini didukung dengan temuan naskahnaskah kesastraan yang dipergunakan scbagai data tambahan dalam penyusunan sejarah Indonesia Kuno.

Masih menurut Wibowo, bahwa salah satu tonggak awal yang signifikan dalam bidang penelitian epigrafi dibuat oleh Friederich melalui prosedur penelitian yang diciptakannya (Wibowo 1976: 66). Hasil penelitian Friederich yang dipublikasikan sekitar tahun 1850-1858 selalu mempergunakan format atau sistematika penyajian yang sekaligus sebenarnya juga memperlihatkannya sebagai prosedur penelitian yang dipakainya. Sistematika penulisan yang digunakannya adalah sebagai berikut (Ibid.):

1. Kata Pengantar, yang berisi tentang deskripsi singkat prasasti yang dibahas dan tinjauan pustaka terhadap prasasti itu sendiri.

2. Hasil Pembacaan dan Penerjemahan

3. Bagian Komentar (Comentarius), yang berisi pertanggungjawaban Friederich terhadap hasil pembacaan dan terjemahan yang dibuatnya.

4. Bagian Tafsiran Prasasti, yang disebutnya dengan istilah Aanmerkingen dan berisi kupasan dan tafsiran isi prasasti.

Prosedur atau tahap penelitian prasasti semacam ini di kemudian hari menjadi sebuah prosedur yang standard yang diikuti banyak peneliti dan bahkan sampai sekarang masih sering dipergunakan.

Boechari (1977) berpendapat bahwa pengetahuan tentang epigrafi akan banyak memberikan sumbangannya terhadap penyusunan sejarah kuno Indonesia. Dalam tulisannya tersebut, selain diuraikan tentang perdebatan-perdebatan teoritis para peneliti terdahulu terhadap peristiwa-peristiwa historis dalam sejarah kuno Indonesia, juga ditekankannya pentingnya pendekatan struktural terhadap unsur-unsur bagian prasasti dalam pemahaman isi prasasti.

Machi Suhadi (1982) membahas perkembangan penelitian epigrafi lebih pada perkembangan teknis mctode penclitian, seperti tcknologi pembuatan dokumen prasasti (fotografi dan abklatsch) dan kodifikasi prasasti. Selanjutnya, Machi Suhadi berpendapat bahwa modernisasi penelitian merupakan syarat mutlak dalam penelitian epigrafi agar tidak tertinggal jauh dari perkembangan ilmu yang lain. Modernisasi penelitian dapat dilakukan antara lain dengan penggunaan alat-alat yang dapat mempermudah dan mempereepat kerja peneliti dalam mengamati prasasti. Akhirnya, diprediksikan bahwa dalam jangka waktu 20 tahun (scjak tulisan tersebut disusun) tidak akan terjadi banyak kemajuan dalam bidang penggunaan teknologi baru. 
Ayatrohaedi (1991) mengemukakan pendapat bahwa bidang epigrafi di Indonesia sebaiknya dikelola oleh jurusan sejarah, bukan oleh jurusan arkeologi seperti yang selama ini terjadi. Lepas dari permasalahan tersebut, Ayotrohaedi menyarankan sebuah program pengembangan epigrafi secara akademis. "Kurikulum" program kajian epigrafi yang diajukannya cukup menarik, yaitu ada enam program pengajaran yang semuanya berjumlah 40 sks: Pengantar Epigrafi, Paleografi, Epigrafi Indonesia, Bahasa Prasasti, Linguistik, dan Sejarah Indonesia.

Richadiana Kartakusuma (1992/1993) dan Djoko Dwiyanto (1993) mengemukakan bahwa dalam menganalisis sumber tertulis dipergunakan tiga metode penelitian, yaitu: metode penelitian analitis (dengan pendekatan struktural), metode penelitian sintesis (melalui pendekatan Fungsi Kebudayaan), dan metode gabungan penelitian analitis dan sintesis. Metode analitis dilakukan melalui kritik ekstern (deskripsi prasasti) dan kritik intern (transliterasi dan transkripsi). Metode penelitian sintesis dilakukan melalui analisis fungsi kebudayaan dengan structural comparative terhadap aspek-aspek agama, sosial, ekonomi, teknologi, kesenian, dan bahasa untuk merekonstruksi masyarakat Indonesia klasik. Sedangkan metode yang ketiga adalah gabungan antara keduanya, yaitu penelitian analitis dan sintesis dipergunakan untuk merekonstruksi kehidupan masyarakat Indonesia pada masa klasik.

Titi Surti Nastiti dalam salah satu bagian utama makalahnya pada Seminar Nasional Metodologi Riset Arkeologi di Universitas Indonesia (1995) mengemukakan tentang metodologi penelitian epigrafi dan sejarah kuna. Titi Surti Nastiti (1995: 6) berpendapat bahwa pada dasarnya metode penelitian epigrafi hampir sama dengan metode penelitian sejarah karena epigrafi sebenamya merupakan bagian dari ilmu sejarah. Penelitian epigrafi diawali dengan dengan kritik sumber, yaitu kritik ekstem dan kritik intern untuk mengetahui keotentikan dan kredibilitas prasasti yang diteliti. Selanjutnya prasasti tersebut ban dapat dipakai untuk merekonstruksi sejarah Indonesia kuno sebagai sumber data penulisan dan bahan acuannya. Nastiti juga melihat bahwa metode penalaran yang umum dipergunakan dalam penelitian epigrafi Indonesia adalah metode induktif. Lebih jauh lagi ia menawarkan untuk mencoba metode gabungan induktif-deduktif yang menurutnya mungkin dapat mendorong penelitian epigrafi yang lebih berbasis pada orientasi masalah (1995: 7).

Daud Aris Tanudirjo (1994) mengemukakan kemungkinan model penelitian lain untuk meneliti sumber tertulis di Indonesia. Ia menawarkan metode hermeneutik yang biasa dipergunakan oleh kajian arkeologi pasca-prosesual untuk meneliti sumber-sumber tertulis. Model yang dibangun adalah sebuah model penelitian yang terdiri dari tiga tahap penelitian yang dalam setiap tahap selalu dilakukan kajian hermeneutik. Tahap 
penelitian yang pertama adalah tahap pencarian informasi primer yang meliputi informasi intern (seperti bentuk, bahan, bahasa, aksara, dsb.) dan informasi ekstern (antara lain kontcks temuan, lingkungan, kepemilikan prasasti, dsb.). Tahap yang kedua adalah tahap untuk menemukan informasi sekunder, yaitu mcliputi aspek fungsi, tujuan, struktur, dan arti pola atribut tertentu. Dalam tahap inilah kegiatan transkripsi dan penterjemahan dilakukan. Tahap ketiga merupakan tahap analisis isi atau penafsiran prasasti. Dalam tahap ini akan dilacak setiap informasi yang implisit maupun eksplisit yang terdapat dalam sumber tertulis. Dalam ketiga tahap penelitian tersebut, sekali lagi, lingkaran hermeneutik dioperasikan terus menerus.

\section{Di antara Arkeologi dan Ilmu Sejarah}

Dari uraian di atas, jelas sekali terlihat bahwa secara epistemologi dan metodologi epigrafi tidak dapat diklasifikasikan scbagai salah satu bagian kajian arkeologi. Saya berpendapat epigrafi lebih tepat disebut sebagai ilmu bantu (anxiliary descipline) bagi kajian arkeologi.

Arkeologi memiliki definisi yang bervariasi; arkeologi didefinisikan menurut kerangka pikir si pencetusnya. Oleh karena itu untuk memberi gambaran tentang ruang lingkup arkeologi yang cukup longgar akan dikemukakan definisi yang cukup luas. Menurut saya, definisi arkeologi yang dapat mewakilinya antara lain adalah definisi yang dikemukakan oleh Michael Brian Schiffer, sebagai seorang penganut behavioral archaeology. Pada dasamya menurut Schiffer (1995: 35) arkeologi adalah "the study of relationships between human behavior and material culture in all times and all places". Renfrew (1993: 41-42) lebih jauh lagi memberikan apa yang disebut dengan "kategori dasar tinggalan arkeologis" yang terdiri dari "artifacts, features, structures, and ecofacts (nonartifactual organic and environmental remains)".

Prasasti sebagai salah satu wujud hasil budaya bendawi (material culture) seharusnya merupakan obyek kajian arkeologi pula, lebih-lebih prasasti sarat makna baik dalam konteks pembuatannya maupun konteks isinya. Dari kajian prasasti akan dapat diungkapkan hubungan antara masyarakat dengan prasastinya sendiri sebagai hasil budaya bendavi. Namun, inti dari kajian epigrafi sebenarnya terletak pada kajian prasasti scbagai teks, bukan semata-mata prasasti sebagai artefak. Kegiatan utama dalam kajian epigrafi adalah membaca dan menafsirkan prasasti, sehingga kajiannya lebih bersifat tekstual. Sedangkan kajian arkeologis biasanya lebih bersifat kontekstual (Renfrew, 1993: 10, 42-44). 
Dengan demikian kedudukan epigrafi sebenarnya berada di luar kajian arkeologi, dan epigrafi hanya berperan sebagai ilmu bantu bagi arkeologi. Epigrafi mempunyai kedudukan dan peran seperti ilmu-ilmu bantu lain dalam arkeologi seperti geologi, sosiologi, antropologi budaya, ilmu ekonomi, dan ilmu politik. Namun demikian, ada juga peneliti yang tetap memasukkan dalam kajian arkeologi dengan menyebutnya sebagai text-added archaeology (Tanudirjo 1991 dan 1994: 1).

Di pihak lain ada juga peneliti yang berpendapat bahwa epigrafi lebih sesuai dengan dengan kajian ilmu sejarah (Titi Surti Nastiti 1995: 6), bahkan Ayatrohaedi (1991) menyarankan agar secara akademik bidang kajian epigrafi diampu oleh jurusan sejarah, bukan oleh jurusan arkeologi. Akan tetapi, pada kenyataannya epigrafi bagi seorang sejarawan tetap juga dianggap sebagai ilmu bantu. Dalam kajian sejarah, epigrafi punya kedudukan dan peran yang sama dengan ilmu bantu (auxiliary sciences) yang lain seperti numismatik, geografi, filsafat, antopologi, dan sebagainya (Garraghan 1957: 81-102). Hal ini mungkin disebabkan oleh karena kajian epigrafi banyak menelaah dan membaca tulisan-tulisan kuno serta menterjemahkan ke dalam bahasa kontemporer. sehingga nampaknya banyak melibatkan bidang ilmu linguistik dan bahasa.

\section{Epigrafi Indonesia: di masa yang akan datang.}

Sudah menjadi pengetahuan umum bahwa SDM yang bergerak dalam bidang kajian epigrafi sangat sedikit (Machi Suhadi 1982: 67; Richadiana Kartakusuma 1992/1993; Prasodjo 1992: 122). Berdasarkan pengalaman saya mengajar di Jurusan Arkeologi Fakultas Sastra Universitas Gadjah Mada, mahasiswa yang berminat mengambil spesialisasi epigrafi hanya berkisar 1-3 orang untuk setiap angkatan. Konsekuensi logisnya adalah bahwa penulisan skripsi dengan topik epigrafi dan sejarah kuna pun juga sedikit. Pemantauan sekilas yang dilakukan terhadap skripsi di Jurusan Arkeologi FS-UGM dengan topik epigrafi dan sejarah kuna mendapatkan data kuantitatif sebagai berikut:

\begin{tabular}{|c|r|}
\hline $\begin{array}{c}\text { Jangka Waktu } \\
\text { (Tahun) }\end{array}$ & $\begin{array}{c}\text { Jumlah } \\
\text { Skripsi }\end{array}$ \\
\hline $1971-1975$ & 2 \\
\hline $1976-1980$ & 0 \\
\hline $1981-1985$ & 4 \\
\hline $1986-1990$ & 6 \\
\hline $1991-1995$ & 14 \\
\hline $1995-1998$ & 3 \\
\hline
\end{tabular}


Sedikitnya kuantitas penulisan skripsi epigrafi dan sejarah kuna ini tentunya dapat dijadikan ccrminan akan kurangnya penelitian dan publikasi cpigrafi dan sejarah kuna secara umum. Melihat kecenderungan data kuantitatif peminat epigrafi yang telah lalu, maka di masa mendatang nampaknya jumlah peneliti epigrafi pun akan tetap sedikit.

Namun demikian, kecilnya kuantitas peneliti kajian epigrafi tidak berarti menurunnya kualitas penelitian epigrafi, justru kondisi ini hendaknya menjadi pemacu bagi peningkatan dan kemajuan mutu penelitian cpigrafi di Indonesia. Di bawah ini disajikan prediksi arah penelitian dan beberapa kemungkinan yang mungkin dapat dilakukan dalam memperkembangkan penelitian epigrafi Indonesia. Perubahan, perkembangan, serta kemungkinan pegembangan kajian epigrafi Indonesia diperkirakan akan terjadi pada metodologi penelitian dan pendekatan-pendekatan baru akan mulai dipergunakan.

Oleh karena metodologi epigrafi lebih dekat pada ilmu sejarah dibandingkan dengan arkeologi, maka nampaknya penyempurnaan metodologi penelitian dapat dilakukan dengan bantuan perspektif ilmu sejarah. Satu hal pokok yang perlu selalu mendapatkan perhatian adalah tentang prasasti sebagai sumber sejarah. Problem yang sama dihadapi oleh kajian epigrafi dan ilmu sejarah bahwa hambatan harus dihilangkan untuk dapat sclalu meninjau ulang sumber-sumber sejarah. Kehati-hatian terhadap sumber dan dilakukannya kritik sumber yang memadai adalah syarat utama untuk dapat menyusun sebuah historiografi yang baik (Taufik Abdullah, 1985: xxiv). Mungkin di masa mendatang akan ada "dialog akademis" yang lebih intensif tentang pengembangan metode kritik sumber antara bidang ilmu epigrafi dengan ilmu sejarah yang tentunya memiliki lebih banyak pengalaman dalam bidang itu.

Masih berkaitan dengan kritik sumber, di sini peranan kajian linguistik juga akan mengambil peranan, terutama bagaimana melihat perbedaan bahasa prasasti yang dipergunakan oleh sebuah prasasti maupun dalam sekelompok prasasti. Kemungkinan penerapan kajian bahasa seperti ini akan sangat bermanfaat untuk melakukan kritik sumber, seperti misalnya penentuan prasasti otentik/asli, timulad otentik/salinan, dan timulad (kategori yang dikemukakan oleh Richadiana Kartakusuma, 1992/1993: 48) berdasarkan kajian linguistik.

Berdasarkan perbandingan bahasa yang dipergunakan dalam prasasti, apakah dapat juga dibedakan persebaran pendukung bahasa prasasti. Studi tentang persebaran bahasa yang dikaitkan dengan persebaran dan asal-usul kelompok masyarakat sudah pernah dicoba oleh Colin Renfrew (1987) yang mengamati keterkaitan tinggalan arkeologi, bahasa, dan asal-usul masyarakat Indo-Eropa. Kemungkinan penerapan kajian seperti itu di Indonesia sangat mungkin dilakukan. Makalah tentang prasasti 
berbahasa Melayu Kuno yang disajikan oleh Dr. Riboet Darmosoetopo dalam seminar ini dan oleh Richadiana Kartakusuma di EHPA 1998 mungkin merupakan awal yang baik dari kajian persebaran bahasa kuno di Indonesia. Kajian tersebut kemungkinan tidak saja berhenti pada persebarannya secara spasial tetapi juga sampai pada interaksi masyarakat pendukung bahasa kuno tersebut, baik yang terjadi di antara pendukung bahasa yang sama yang tersebar dalam jarak ruang yang luas maupun antar pendukung bahasa vang berlainan.

Selain kemungkinan aplikasi pendekatan-pendekatan dari kajian linguistik dan ilmu sejarah, tampaknya beberapa pendekatan yang digunakan di arkeologi dapat pula diserap. Contoh yang representatif dari penggunaan pendekatan arkeologis yang dicobaterapkan dalam kajian epigrafi adalah makalah yang ditulis oleh Daud Aris Tanudirjo (1994) yang sudah diuraikan di bagian atas. Penggunaan pendekatan hermeneutik, yang sebenarnya juga diambil olch arkeologi dari bidang ilmu lain. ternyata sangat dapat mengoptimalkan penafsiran dan interpretasi data prasasti. Pendekatan-pendekatan arkeologis lainnya tentunya masih banyak yang dapat dipergunakan dalam kajian epigrafi.

Kajian epigrafi sendiri di masa akan datang tentunya juga akan bergerak ke arah yang lebih "memasyarakat". Dalam arti bahwa gerak kegiatan epigrafi tidak hanya sekedar pergumulan ilmiah saja, tetapi juga lebih memaksimalkan sumbangan ilmu tersebut bagi masyarakat. Ada dua hal yang perlu dilakukan untuk memasyarakatkan epigrafi. Pertama, meningkatkan jumlah publikasi populer tentang epigrafi. Buku tulisan Aan Kumar dan John H. McGlynn (1996) yang berjudul "Illuminatons. The Writing Traditions of Indonesia" dapat dijadikan contoh usaha mendekatkan dan mempopulerkan epigrafi kepada masyarakat. Upaya kedua adalah dengan meningkatkan atau memperbanyak penelitian epigrafi yang lebih "membumi" atau dengan topik-topik penelitian yang dekat dengan masyarakat. Misalnya melakukan kajian epigrafi terhadap tulisan-tulisan kotemporer, seperti grafiti.

\section{Penutup}

Akhirnya, sekali lagi saya menegaskan bahwa epigrafi merupakan ilmu bantu bagi arkeologi dan ilmu sejarah. Dengan mengetahui posisi epigrafi dalam konstelasi bidang kajian yang lain, kita akan tahu dimana kita berpijak untuk kemudian dapat mengembangkan bidang kajian epigrafi ini. Pengembangan kajian epigrafi itu sendiri ternyata cukup cerah. Masih banyak yang dapat kita lakukan untuk meningkatkan kuantitas dan kualitas penelitian epigrafi. 


\section{KEPUSTAKAAN}

Ayatrohaedi. 1991. "Epigrafi Indonesia dan Pengembangannya". Diskusi Ilmiah Epigrafi. Yogyakarta, 9-10 November 1991.

Boechari. 1977. "Epigrafi dan Sejarah Indonesia". Majalah Arkeologi. Th. I, No. 2 , 1977. Hlm. 1-32.

Djoko Dwiyanto, Drs. 1993. "Dialog: Metode Penelitian Epigrafi dalam Arkeologi”, Artefak. No. 13-Agustus 1993. Hlm. 7-8.

Garraghan, Gilhert J. 1957. A Guide to Hitorical Method. New York: Fordan University Press.

Kumar, Aan and John H. McGlynn. 1996. Illuminations. The Writing Traditions of Indonesia. Jakarta: The Lontar Foundation.

Machi Suhadi. 1982. "Penelitian Prasasti di Indonesia". Dalam: Lokakarya Arkeologi Tahun 1978. Jakarta: Pusat Penelitian Arkeologi Nasional.

Prasodjo, Tjahjono. 1992. "Kecenderungan, Arah, dan Prospek Studi Paleografi Klasik di Indonesia". PIA VI. Batu, 26-30 Juli 1992.

Renfrew, Colin. 1987. Archaeology and Language. London: Penguin Books.

Renfrew, Colin and Paul Bahn. 1993. Archaeology: Theories, Methods, and Practice. London: Thames and Hudson Ltd.

Richadiana Kartakusuma. 1992/1993. "Prof. Boechari dan Penelitian Epigrafi Indonesia". Kebudayaan, No. 4 Th. II 1992/1993. Hlm. 43-50, 91.

1998. "Persebaran Prasasti Berbahasa Melayu Kuna di Pulau Jawa". Evaluqsi Hasil Penelitian Arkeologi. Cipayung, 16-20 Februari 1998.

Schiffer, Michael Brian. 1995, "Social Theory and History in Behavioral Archaeology". Dalam: James M. Skibo, William H. Walker and Axel E. Nielsen (eds.) Expanding Archaeology. Salt Lake City: University of Utah Press. HIm. 22-35. 
Tanudirjo, Daud Aris. 1991. "Theortical Trends in Indonesian Archaeology". A paper presented in the Theoretical Archaeology Group Southampton, December 1991 .

Tanudirjo, Daud Aris. 1994. "Epigrafi Indonesia dalam Kerangka Pikir PascaModernisme", makalah yang disajikan dalam: Seminar Evaluasi Data dan Interpretasi Baru Sejarah Indonesia Kuna. Yogyakarta, 23-24 Maret 1994.

Taufik Abdullah dan Abdurrachman Surjomihardjo (eds.). 1985. Ilmu Sejarah dan Historiografi. Arah dan Perspektif. Jakarta: Penerbit PT Gramedia.

Titi Surti Nastiti. 1995. "Metodologi Riset: Bidang Epigrafi dan Sejarah Kuna". Seminar Nasional Metodologi Riset Arkeologi. Depok, 23-24 Januarı 1995.

Wibowo, A.S. 1976. "Riwayat Penyelidikan Prasasti di Indonesia", dalam: Satyawati Suleiman (ed.). 50 Tahun Lembaga Purbakala 1913-1963. Jakarta: Pusat Penelitian Arkeologi Nasional. HIm. 60-103.

\section{Ucapan Terima Kasih}

Diucapkan banyak terima kasih kepada Drs. Djoko Dwiyanto, Drs. Daud Aris Tanudirjo MA., Dra. DS. Nugrahani MA.. dan Dra. Endah Setyowati yang telah bersedia meluangkan waktu dan pikirannya untuk berdiskusi dengan saya dalam upaya penyempurnaan makalah ini. Ucapan terima kasih juga disampaikan buat Didik Suhartono yang telah mempersiapkan data skripsi epigrafi yang dipergunakan dalam makalah ini. Namun demikian. semua gagasan dan (jika terdapat) kesalahan-kesalahan dalam makalah ini akan menjadi tanggung jawab penulis sepenuhnya 